\title{
Perfil da contagem de células somáticas na infecção intramamária em búfalas na Região Nordeste do Brasil ${ }^{1}$
}

\author{
Elizabeth S. Medeiros ${ }^{2}$, Severino Benone Paes Barbosa ${ }^{3}$, Raquel \\ Bezerra Jatobá ${ }^{3}$, Sérgio Santos Azevedo ${ }^{4}$, José Wilton Pinheiro Junior ${ }^{5}$, \\ Tomoe Noda Saukas ${ }^{6}$, Pedro Paulo Feitosa de Albuquerque ${ }^{6}$ \\ e Rinaldo Aparecido Mota ${ }^{*}$
}

\begin{abstract}
Medeiros E.S., Barbosa S.B.P., Jatobá R.B., Azevedo S.S., Pinheiro Junior J.W., Saukas T.N., Albuquerque P.P.F. \& Mota R.A. 2011. [Somatic cell count profile in intramammary infection of buffaloes from the Brazilian Northeast.] Perfil da contagem de células somáticas na infecção intramamária em búfalas na Região Nordeste do Brasil. Pesquisa Veterinária Brasileira 31(3):219-223. Departamento de Medicina Veterinária, Universidade Federal Rural de Pernambuco, Rua Dom Manoel de Medeiros s/n, Dois Irmãos, Recife, PE 51171-900, Brazil. E-mail: rinaldo.mota@ hotmail.com

The aim of this study was to evaluate the somatic cell profile in the subclinical mastitis in dairy buffaloes in the Brazilian Northeastern. One thousand eight hundred ninety six milk samples from 474 buffaloes proceeding from four dairy farms located in the states of Pernambuco, Alagoas, Bahia and Ceará were analyzed. The lactic secretion was submitted to the California Mastitis Test (CMT) and the positive samples, from two crosses on were collected for the somatic cell count (SCC) and microbiologic exam. It was observed that the positive samples at the microbiologic exam presented SCC between 280,000 and 401,000 cells $/ \mathrm{mL}$ with median of 328,000 cells $/ \mathrm{mL}$. It was concluded that SCC values above 280,000 cells $/ \mathrm{mL}$ is an indication of mammary gland infection, however, the microbiologic exam of the milk is the best method for the diagnostic of subclinical mastitis in buffaloes. The observation of Staphylococcus coagulase-negative exerting influence in the SCC elevation must be subject of further studies in order to elucidate the pathogenicity of this group of microorganisms in mastitis of buffaloes.
\end{abstract}

INDEX TERMS: Milk, buffaloes, mastitis, microbiology, somatic cell count, diagnosis.

\footnotetext{
${ }^{1}$ Recebido em 10 de maio de 2010.

Aceito para publicação em 2 de outubro de 2010.

Parte da Tese de Doutorado em Biociência Animal do primeiro autor.

2 Campus Arapiraca, Universidade Federal de Alagoas, Pólo Viçosa, Fazenda de São Luís s/n, Zona Rural, Viçosa, AL 57700-000, Brasil.

${ }^{3}$ Departamento de Zootecnia, Universidade Federal Rural de Pernambuco (UFRPE), Rua Dom Manoel de Medeiros s/n, Dois Irmãos, Recife, PE 51171-900, Brasil

${ }^{4}$ Centro de Saúde e Tecnologia Rural, Universidade Federal de Campina Grande, Av. Universitária s/n, Santa Cecília, Patos, PB 58700970, Brasil

${ }^{5}$ Unidade Acadêmica de Garanhuns, Universidade Federal Rural de Pernambuco, Av. Bom Pastor s/n, Boa Vista, Garanhuns, PE 55296901, Brasil.

${ }^{6}$ Departamento de Medicina Veterinária, UFRPE, Rua Dom Manoel de Medeiros s/n, Dois Irmãos, Recife, PE 51171-900. *Autor para correspondência: rinaldo.mota@ hotmail.com
}

RESUMO.- Objetivou-se com esse estudo avaliar o perfil de células somáticas na mastite subclínica em búfalas leiteiras no Nordeste do Brasil. Foram analisadas 1896 amostras de leite de 474 búfalas procedentes de quatro propriedades de exploração leiteira nos Estados de Pernambuco, Alagoas, Bahia e Ceará. A secreção láctea de cada teto foi submetida ao Califórnia Mastitis Test (CMT) e as amostras positivas, a partir de duas cruzes foram coletadas para realização da contagem de células somáticas (CCS) e exame microbiológico. Observou-se que as amostras positivas no exame microbiológico apresenta$\mathrm{ram}$ CCS entre 280.000 a $401.000 \mathrm{cel} / \mathrm{mL} \mathrm{com}$ mediana de $328.000 \mathrm{cel} / \mathrm{mL}$. Conclui-se que valores de CCS acima de $280.000 \mathrm{cel} / \mathrm{mL}$ é um indicativo de infecção da glândula mamária, contudo o exame microbiológico do leite é o melhor método para diagnóstico da mastite subclínica em búfalas. A observação dos Staphylococcus coagulase 
negativa exercendo influência na elevação da CCS deve ser objeto de outros estudos para elucidar a patogenicidade desse grupo de microrganismos na mastite de búfalas.

TERMOS DE INDEXAÇÃO: Leite, búfalos, mastite, microbiologia, contagem de células somáticas, diagnóstico.

\section{INTRODUÇÃO}

A expressão "células somáticas" é aplicada para designar leucócitos e células epiteliais provenientes da esfoliação dos ácinos galactóforos do úbere, cisterna mamária e cisterna do teto e são eliminadas no leite durante o curso normal da lactação (Galiero \& Morena 2000). A inflamação da glândula mamária resultante da introdução e multiplicação de microrganismos patogênicos conduz a uma série complexa de eventos que reduz a atividade sintética da glândula, provoca mudanças na composição do leite e eleva a contagem de células somáticas (CCS). A CCS, sendo uma expressão direta da severidade do processo inflamatório, é o parâmetro usualmente utilizado para avaliar a saúde do úbere em relação à qualidade e higiene do leite e monitoramento em programas de controle de mastites (Harmon 1994).

Ao considerar leite de conjunto, em 1994, a legislação da Comunidade Européia determinou que o leite de origem bovina, caprina, ovina ou bubalina, quando destinado ao consumo humano deve apresentar, entre outras características, uma contagem máxima de células somáticas de 400.000 células/mL (Bierens 1993).

Para búfalas, no Brasil, ainda não existe uma legislação que regulamente o padrão de CCS e o uso de parâmetros utilizados para bovinos de CCS tem-se mostrado inadequado, pois os valores das contagens são significantemente menores em bubalinos do que nos bovinos (Amaral 2005, Araújo \& Gheller 2005).

Piccinini et al. (2006) sugeriram a contagem de 400.000 células $/ \mathrm{mL}$ como ponto de triagem para o leite bubalino. Entretanto, diversos autores adotaram o valor de 500.000 células $/ \mathrm{mL}$ para selecionar os quartos com presença ou ausência do quadro subclínico, sem necessariamente utilizarem a confirmação microbiológica (Vianni et al. 1990, Tuteja et al. 2001, Singh et al. 2002, Vivek et al. 2002, Dhakal 2004, Singh et al. 2004).

Búfalas com elevada CCS apresentam redução da produção de leite (Petrova \& Tzankova 1999, Ceron-Muñoz et al. 2002a, Tripaldi et al. 2003), alterações dos teores de seus constituintes (Petrova \& Tzankova 1999, Tripaldi et al. 2003) e alterações no tempo de coagulação do leite no processo de fabricação de queijos, comprometendo a qualidade, processamento e rendimento industrial (Tripaldi et al. 2003).

Considerando o reduzido número de trabalhos envolvendo a qualidade do leite de búfalos no Brasil, objetivouse com esse estudo avaliar o perfil de células somáticas e a mastite subclínica em búfalas no Nordeste do Brasil.

\section{MATERIAL E MÉTODOS}

Foram analisadas 1896 amostras de leite de 474 búfalas procedentes de quatro propriedades de exploração leiteira situa- das nos Estados de Pernambuco, Alagoas, Bahia e Ceará. Os rebanhos eram constituídos de animais de diferentes idades, da raça Murrah e seus mestiços e se encontravam em diferentes estágios de lactação. Eram criados em sistema intensivo ou semi-intensivo e submetidos à ordenha mecânica canalizada ou balde ao pé.

A secreção láctea de cada teto foi submetida ao Califórnia Mastitis Test (CMT) (Schalm \& Noorlander 1957). As amostras positivas ao CMT, a partir de duas cruzes (641 amostras) foram coletadas para a avaliação da CCS e realização do exame microbiológico.

Para avaliação da CCS, as amostras foram acondicionadas em frascos apropriados contendo o conservante Bronopol ${ }^{7}$, sendo imediatamente refrigeradas e encaminhadas ao laboratório. A contagem de células somáticas foi realizada no Laboratório da Rede Brasileira de Qualidade do leite na Universidade Federal Rural de Pernambuco, Recife, por meio de equipamento eletrônico SomaCount 300 pelo método de citometria de fluxo (IDF 1995).

As amostras de leite para as análises microbiológicas foram obtidas após prévia lavagem do úbere com água e sabão, secagem com papel toalha e anti-sepsia do óstio do teto com álcool a $70^{\circ} \mathrm{GL}$. Coletaram-se aproximadamente cinco $\mathrm{mL}$ de leite em frascos com tampa rosqueável, esterilizados e previamente identificados com o nome ou número do animal e quarto mamário, sendo enviadas ao laboratório em caixas isotérmicas contendo gelo reciclável para processamento no laboratório de Bacterioses dos Animais Domésticos da UFRPE.

Alíquotas de $10 \mu \mathrm{L}$ de leite foram semeadas em placas de ágar base enriquecido com $5 \%$ de sangue ovino e posteriormente foram incubadas em estufa bacteriológica a $37^{\circ} \mathrm{C}$, realizando-se leituras após 24, 48h e 72h. Posteriormente foram observadas as características morfológicas das colônias como tamanho, tipo, coloração e presença de hemólise. Ao microscópio foram observadas a disposição das células e as características morfotintorias à técnica do Gram (Carter 1991).

A classificação das bactérias Gram positivas foi realizada de acordo com Quinn et al. (1994). Para a identificação dos isolados de Staphylococcus spp. foram realizadas provas bioquímicas como produção de coagulase livre, DNase e catalase, segundo Silva et al. (1997). As provas de produção de acetoína, fermentação da glicose (anaerobiose) e do manitol (aerobiose e anaerobiose) foram realizadas de acordo com Mac Faddin (1980). Os isolados foram classificados em Staphylococcus aureus (S. aureus), quando positivo em todos os testes, Staphylococcus coagulase positiva (SCP), quando positivo para a produção da coagulase, fermentação da glicose em anaerobiose e catalase, mas negativo em algum dos outros testes. Em Staphylococcus coagulase negativa (SCN) quando a bactéria não coagulava o plasma de coeIho, apresentava características de estafilococos na técnica de coloração de Gram, fermentava a glicose em anaerobiose e produzia a catalase (Baird-Parker 1990).

Para a identificação das enterobactérias foram utilizadas as seguintes provas bioquímicas: produção de urease, reação em Ágar Tríplice Açúcar Ferro (TSI), teste de VM/VP (VM - reação de Vermelho de Metila; VP - reação de Voges-Proskauer), teste em Ágar SIM (S - produção de $\mathrm{H}_{2} \mathrm{~S}$; I - produção de Indol; M - motilidade) e teste em Ágar Citrato (utilização do carbono do citrato), sendo identificadas de acordo com Carter (1991).

Para a avaliação da CCS frente ao cultivo microbiológico

\footnotetext{
${ }^{7}$ Bronopol $($, D \& F Control Systems, Dublin, USA.
} 
(padrão ouro), foram calculados sensibilidade, especificidade e indicador de concordância Kappa (Pereira 1995). O teste de hipóteses foi efetuado com o teste de McNemar, com nível de significância de 5\% (Siegel \& Castellan Jr 2006). As análises foram efetuadas com o programa DagStat (Mackinnon 2000).

$\mathrm{Na}$ comparação da contagem de células somáticas entre amostras positivas e negativas no cultivo microbiológico, foi utilizada a mediana como medida de tendência central, uma vez que os dados não apresentaram distribuição normal. A comparação entre os dois grupos (positivas e negativas no cultivo) foi realizada com o teste não paramétrico $U$ de MannWhitney. Para as comparações das proporções de agentes isolados no cultivo microbiológico de acordo com o resultado na CCS foi utilizado o teste de qui-quadrado (Zar 1999). O nível de significância adotado foi de $5 \%$ e as análises foram feitas com o programa SPSS for Windows versão 13.0.

\section{RESULTADOS E DISCUSSÃO}

No Quadro 1 encontram-se os resultados da média da CCS em relação ao exame microbiológico. Quando se considerou a média de CCS $(400.000 \mathrm{cel} / \mathrm{mL})$ estabelecida por Piccinini et al. (2006) como ponto de corte para o leite de búfala, observou-se que $220(54,9 \%)$ amostras negativas e $181(45,1 \%)$ positivas ao exame microbiológico apresentaram média de CCS $\leq 400.000 \mathrm{cel} / \mathrm{mL}$, respectivamente. Quando a média de CCS foi $>400.000 \mathrm{cel} / \mathrm{mL}$, observouse que $146(60,8 \%)$ amostras foram positivas e $94(39,2 \%)$ negativas no exame microbiológico.

Ao analisar a concordância entre os testes de CCS e exame microbiológico, considerando esse último como o padrão ouro verificou-se uma fraca concordância $(K=0,146)$, sensibilidade de $44,7 \%$ e especificidade de $70,1 \%$ (Quadro 1).

Considerando os resultados obtidos nesse estudo, observou-se que as amostras positivas no exame microbiológico apresentaram CCS entre 280.000 a $401.000 \mathrm{cel} / \mathrm{mL}$ com mediana de $328.000 \mathrm{cel} / \mathrm{mL}$, independente do microrganismo isolado. As amostras negativas no exame microbiológico apresentaram CCS entre 164.000 a $232.000 \mathrm{cel} /$ $\mathrm{mL}$ com mediana de $197.000 \mathrm{cel} / \mathrm{mL}$. Observou-se diferença significativa entre a CCS entre os dois grupos $(p=0,0001)$ (Quadro 2).

Os resultados médios obtidos nesse estudo para considerar as amostras positivas em ambos os testes estão próximos daqueles relatados na literatura internacional e podem ser úteis ao proprietário que utiliza a CCS para ava-

\begin{tabular}{|c|c|c|c|c|c|c|}
\hline \multicolumn{7}{|c|}{$\begin{array}{l}\text { Quadro 1. Resultado da média de CCS frente ao exame } \\
\text { microbiológico em amostras de leite de búfalas em } \\
\text { propriedades no Nordeste do Brasil }\end{array}$} \\
\hline \multirow[t]{3}{*}{ CCS } & \multicolumn{4}{|c|}{ Exame microbiológico } & \multicolumn{2}{|c|}{ Total } \\
\hline & \multicolumn{2}{|c|}{ Negativo } & \multicolumn{2}{|c|}{ Positivo } & \multirow[t]{2}{*}{$\mathrm{N}$} & \multirow[t]{2}{*}{$\%$} \\
\hline & $\mathrm{N}$ & $\%$ & $\mathrm{~N}$ & $\%$ & & \\
\hline$\leq 400$ & 220 & 54,9 & 181 & 45,1 & 401 & 100,0 \\
\hline$>400$ & 94 & 39,2 & 146 & 60,8 & 240 & 100,0 \\
\hline
\end{tabular}

Sensibilidade: $44,7 \%$ (IC 95\% = 39,2\% - 50,2\%).

Especificidade: $70,1 \%$ (IC 95\% = 64,7\% - 75,1\%).

Indicador Kappa: 0,146 (IC 95\% = 0,072 - 0,220); concordância fraca.

Teste de McNemar: $p<0,0001$.

\begin{tabular}{|c|c|c|c|c|}
\hline \multicolumn{5}{|c|}{$\begin{array}{l}\text { Quadro 2. Mediana e intervalo de confiança de } 95 \% \text { (IC } \\
95 \% \text { ) da contagem de células somáticas (CCS) em } \\
\text { amostras de leite de búfalas em propriedades no Nordeste } \\
\text { do Brasil, segundo o resultado do cultivo microbiológico }\end{array}$} \\
\hline \multirow[t]{2}{*}{$\begin{array}{c}\text { Exame } \\
\text { microbiológico }\end{array}$} & \multirow[t]{2}{*}{$\begin{array}{c}\text { № de } \\
\text { amostras }\end{array}$} & \multicolumn{2}{|c|}{$\begin{array}{c}\text { Contagem de células } \\
\text { somáticas }\end{array}$} & \multirow[t]{2}{*}{$p^{*}$} \\
\hline & & Mediana & IC $95 \%$ mediana & \\
\hline Positivo & 327 & 328 & $280-401$ & 0,0001 \\
\hline Negativo & 314 & 197 & 164- 232 & \\
\hline
\end{tabular}

* Teste U de Mann-Whitney

liar a sanidade da glândula mamária dos animais dos rebanhos na região estudada. Ao verificar valores entre 280.000 até $401.000 \mathrm{cel} / \mathrm{mL}$ pode-se suspeitar que a amostra seja positiva e solicitar exame microbiológico para confirmar o agente infeccioso envolvido na infecção intramamária para implantar medidas de profilaxia e controle. Sabe-se que existem outros fatores não infecciosos que também podem elevar a CCS no leite das búfalas como o início e final da ordenha (Dhakal et al. 1991, Bastos 2005), estação do ano (Singh \& Ludri 2001).

Carvalho et al. (2007) relataram que o padrão de contagem de CCS para bubalinos é diferente do normalmente encontrado para bovinos e que os baixos valores de CCS não indicam necessariamente a ausência de infecção intramamária. Esse achado também foi observado no presente estudo, pois algumas amostras com CCS abaixo do limite inferior de $280.000 \mathrm{cel} / \mathrm{ml}$ foram positivas no exame microbiológico. Em outros casos também se observaram amostras de leite com alta CCS e exame microbiológico negativo. Sobre esse aspecto Dhakal et al. (1992) chamaram de processos inflamatórios inespecíficos aqueles que contavam com mais de 500.000 células $/ \mathrm{mL}$ acompanhados de exame microbiológico negativo em amostras de leite de búfalas. Esses resultados demonstram que o exame microbiológico é mais sensível que a CCS na detecção da infecção esse último deve ser utilizado como teste de triagem das amostras. Na impossibilidade de relacionar a CCS com o exame microbiológico alguns autores adotaram o valor de 500.000 células/mL para selecionar os quartos com presença ou ausência do quadro subclínico (Singh et al. 2002, Vivek et al. 2002, Dhakal 2004, Singh et al. 2004).

São poucos os trabalhos de CCS em leite de búfalas realizados no Brasil, e na região Nordeste quase nada se sabe sobre esse parâmetro de avaliação da sanidade da glândula mamária. Muitas vezes se utiliza os parâmetros de CCS para bovinos que podem não ser adequados para monitoramento de mastite em rebanhos bubalinos. Sabe-se que os bubalinos são mais resistentes às infecções intramamárias que os bovinos e apresentam diferenças quantitativas e qualitativas na celularidade do leite (Silva \& Silva 1994). Ainda de acordo com Lau (1994), as búfalas apresentam tetos mais pendulosos, contudo o ductus papilaris é mais musculoso com maior quantidade de fibras e vasos sanguíneos, funcionando como barreira eficiente contra as infecções. Contudo nesse estudo observou-se que a frequência de casos de infecção no exame microbiológico foi 
Quadro 3. Frequência de microorganismos isolados em leite de búfalas segundo o resultado na contagem de células somáticas no Nordeste brasileiro

\begin{tabular}{|c|c|c|c|c|c|c|c|c|c|c|c|c|c|c|}
\hline \multirow[t]{3}{*}{ CCS } & \multicolumn{14}{|c|}{ Exame microbiológico } \\
\hline & \multicolumn{2}{|c|}{$\begin{array}{c}\text { Sem } \\
\text { isolamento }\end{array}$} & \multicolumn{2}{|c|}{$\begin{array}{c}\text { Staphyloccoccus } \\
\text { aureus }\end{array}$} & \multicolumn{2}{|c|}{ SCP } & \multicolumn{2}{|c|}{$\mathrm{SCN}$} & \multicolumn{2}{|c|}{$\begin{array}{l}\text { Corynebac- } \\
\text { terium }\end{array}$} & \multicolumn{2}{|c|}{ Bactérias G } & \multicolumn{2}{|c|}{ Outros } \\
\hline & $\mathrm{N}$ & $\%$ & $\mathrm{~N}$ & $\%$ & $\mathrm{~N}$ & $\%$ & $\mathrm{~N}$ & $\%$ & $\mathrm{~N}$ & $\%$ & $\mathrm{~N}$ & $\%$ & $\mathrm{~N}$ & $\%$ \\
\hline$\leq 400$ & 220 & 54,9 & 2 & 0,5 & 16 & 4 & 69 & 17,2 & 37 & 9,2 & 34 & 8,5 & 23 & 5,7 \\
\hline$>400$ & 94 & 39,3 & 3 & 1,3 & 14 & 5,9 & 52 & 21,8 & 40 & 16,7 & 21 & 8,8 & 15 & 6,3 \\
\hline Total & 314 & 49,1 & 5 & 0,8 & 30 & 4,7 & 121 & 18,9 & 77 & 12 & 55 & 8,6 & 38 & 5,9 \\
\hline
\end{tabular}

elevada correspondendo a 51\% (327/641) das amostras com CMT a partir de 2+. Esses resultados também demonstraram que o CMT não foi eficiente para identificar os verdadeiros positivos no exame microbiológico. Embora alguns autores acreditem que o CMT possa ser empregado como método indireto de auxílio no diagnóstico de mastite subclínica em búfalas, Pardo (2007) observou que existem sérias restrições quanto a essa idéia em função das baixas contagens celulares, tanto na presença quanto na ausência de bactérias nos quartos mamários. Concluíram também que o exame microbiológico se apresentou como a referência mais segura na identificação de quartos acometidos por mastite subclínica envolvendo microrganismos.

Os resultados do presente estudo corroboram parcialmente com os de Moroni et al. (2006) que analisaram microbiologicamente amostras de leite bubalino com CCS acima de $200.000 \mathrm{cel} / \mathrm{mL}$ e observaram a presença de infecção intramamária em $100 \%$ dos quartos, enquanto que $98 \%$ das amostras que apresentaram contagem inferior a este valor foram negativas no exame microbiológico. De acordo com esses autores, esse valor de CCS apresenta uma sensibilidade de $99,1 \%$ especificidade de $100 \%$ na identificação de quartos com e sem infecção, respectivamente. Apesar do limite de CCS semelhante em ambos os estudos para considerar as amostras positivas no exame microbiológico, no presente estudo a sensibilidade e especificidade foram inferiores àquelas relatadas por esse autor. Ainda quando se considerou a CCS acima de 280.000 $\mathrm{cel} / \mathrm{mL}$ para efeito de cálculo da sensibilidade e especificidade não se observou grande variação nesses valores (Sens $=55,8 \%$ e Espec $=62,5 \%$ ).

Cerón-Muñoz et al. (2002b) adotaram a CCS acima de 283.000 células $/ \mathrm{mL}$ como ponto de corte para considerar a presença de mastite subclínica em búfalas, dados que também se aproximam dos obtidos nesse estudo.

Por outro lado, os resultados do presente estudo discordam dos índices de CCS observados por Carvalho et al. (2007) que estudaram a CCS e o isolamento de agentes causadores de mastite em búfalas em oito rebanhos na região do Alto do São Francisco, MG e observaram que as amostras de leite com CCS variando de 12.840 a $149.680 \mathrm{cel} / \mathrm{mL}$ apresentaram infecção por diversos patógenos. No presente estudo, a maioria das amostras que apresentaram CCS entre 164.000 a $232.000 \mathrm{cel} / \mathrm{mL}$ foram negativas no exame microbiológico.

Ainda ao se avaliar o valor mínimo para do intervalo de confiança $(280.000 \mathrm{cel} / \mathrm{mL}$ ) observou-se diferença se comparados aos trabalhos anteriormente realizados por Silva \& Silva (1994) que consideraram a CCS no leite de búfalas normal entre 50.00 e $375.000 \mathrm{cel} / \mathrm{mL}$, enquanto que Galiero \& Morena (2000) relataram valores para a CCS no leite bubalino entre 50.000 e $100.000 \mathrm{cel} / \mathrm{mL}$.

No Quadro 3 observou-se uma maior frequência de bactérias Staphylococcus coagulase negativo $52(21,8 \%)$ seguido do Corynebacterium spp. 40 (16,7\%), bactérias Gram negativas $(8,8 \%)$, Staphylococcus coagulase positiva $(5,9 \%)$, Staphylococcus aureus $(1,3 \%)$ nas amostras de leite com valores de CCS acima de $400.000 \mathrm{cel} / \mathrm{mL}$.

Para bovinos, Zafalon et al. (1999) estudaram a influência de Corynebacterium spp., Staphylococcus spp. coagulase positivos (SCP) e coagulase negativos (SCN) sobre a CCS de quartos mamários com mastite. Comparando os quartos afetados com os sadios, ressaltaram que alguns gêneros bacterianos exercem maior influência sobre a contagem de células somáticas. A maior variação foi determinada pelos SCN que provocaram uma variação de $862,7 \%$, ou seja, uma elevação de 75.000 para 722.000 células $/ \mathrm{mL}$ entre os quartos sadios e os afetados. Seguiram os Staphylococcus coagulase positivos, com elevação de $613,0 \%$ (de 92.000 para 656.000 células $/ \mathrm{mL}$ ) e as Corynebacterium spp. que determinaram variação de $548,2 \%$ (de 137.000 para 888.000 células $/ \mathrm{mL}$ ).

Para búfalas, Kapronezai (2004) relatou valores de mediana para CCS de $8.500 / \mathrm{mL}, 10.350 / \mathrm{mL}$ e $9.600 / \mathrm{mL}$ quando foram isoladas Staphylococcus spp., Streptococcus spp. e Corynebacterium spp., respectivamente. Apesar de nesse estudo não se ter calculado a CCS por microrganismo isolado, a CCS de uma forma geral esteve mais elevada. No presente estudo essa análise não foi realizada, pois se optou por avaliar a presença da infecção independente do microrganismo uma vez que essa é a realidade de campo.

\section{CONCLUSÃO}

Conclui-se que valores de CCS acima de $280.000 \mathrm{cel} / \mathrm{mL}$ são um indicativo de infecção da glândula mamária, contudo o exame microbiológico do leite é o melhor método para diagnóstico da mastite subclínica em búfalas. A observação de Staphylococcus coagulase negativa exercendo influência na elevação da CCS deve ser objeto de outros estudos para elucidar a patogenicidade desse grupo de microrganismos nos processo inflamatório da glândula mamária de búfalas. 


\section{REFERÊNCIAS}

Amaral F.R. 2005. Fatores que interferem na contagem de células somáticas e constituintes do leite de búfalas. Dissertação de Mestrado em Medicina Veterinária Preventiva, Escola de Veterinária, Universidade Federal de Minas Gerais, Belo Horizonte, MG. 46p.

Araújo D.K.G. \& Gheller V.A. 2005. Aspectos morfológicos, celulares e moleculares da imunidade da glândula mamária de búfalas (BubaIus bubalis): revisão de literatura. Revta Bras. Reprod. Anim. 29:7783.

Baird-Parker A.C. 1990. The Staphylococci: An introduction. J. Appl. Bacteriol. 19:15-85.

Bastos P.A.S. 2005. Constituição físico-química, celular e microbiológica do leite de búfalas (Bubalus bubalis) criadas no Estado de São Paulo. Boletim do Búfalo, Associação Brasileira dos Criadores de Búfalos, 2:38.

Bierens M. 1993. Stricter hygiene regulations for milk and milk products from 1994. Lait et Nous 3:22-23.

Carter G.R. \& Chengappa M.M. 1991. Brucella, p.196-201. In: Carter G.R. \& Chengappa M.M. (Eds), Essentials of Veterinary Bacteriology and Mycology. $4^{\text {th }}$ ed. W.B. Saunders, Philadelphia.

Carvalho L.B., Amaral F.R., Brito M.A.V.P., Lange C.C., Brito J.R.F. \& Leite R.C. 2007. Contagem de células somáticas e isolamento de agentes causadores de mastite em búfalas (Bubalus bubalis). Arq. Bras. Med. Vet. Zootec. 59:242-245.

Cerón-Muñoz M., Tonhati H., Duarte J., Muñoz-Berrocal M. \& JuradoGámez H. 2002a. Factors affecting somatic cell counts and their relations with milk and milk constituent yield in buffaloes. J. Dairy Sci. 85:2885-2889.

Cerón-Muñoz M., Tonhati H. \& Duarte J.M.C. 2002b. Contagem de células somáticas e produção de leite em bubalinos. Revta Inst. Latic. Cândido Tostes 57:8-10.

Dhakal I.P., Kapur M.P. \& Bhardwaj R.M. 1991. Diagnosis of subclinical mastitis in buffaloes using somatic and viable cell counts. Indian J. Dairy Sci. 44:585-586.

Dhakal I.P., Kapur M.P. \& Anshu S. 1992. Significance of differential somatic cell counts in milk for the diagnosis of subclinical mastitis in buffaloes using foremilk and stripping milk. Indian J. Anim. Health 31:39-42.

Dhakal I.P. 2004. Normal somatic cell count and subclinical mastitis in Murrah buffaloes. Buffalo J. 20:261-270.

Galiero G. \& Morena C. 2000. The meaning of the somatic cell count in buffalo milk. Bubalus bubalis 4:26-27.

Harmon R.J. 1994. Physiology of mastitis and factors affecting somatic cell counts. J. Dairy Sci. 77:2103-2112.

International Dairy Federation 1995. Milk: Enumeration of somatic cells. IDF Standard 148. 8p.

Kapronezai J. 2004. Estudo de provas microbiológicas e celulares em amostras de leite provenientes de fêmeas bubalinas (Bubalus bubalis) no Estado de São Paulo. Dissertação de Mestrado, Faculdade de Medicina Veterinária e Zootecnia, USP, São Paulo, SP. 82p.

Láu H.D. 1994. Important economic diseases in buffaloes. Proc. World Buffalo Congress, São Paulo, SP, p.209-220.

MacFadin J. 1980. Pruebas bioquímicas para la identification de bactérias de interesse clínico. Panamericana, Buenos Aires. 301p.

Mackinnon A.A. 2000. A spreadsheet for the calculation of comprehensive statistics for the assessment of diagnostic tests and inter-rater agreement. Comput. Biol. Med. 303:127-134.

Moroni P., Sgoifo Rossi C., Pisoni G., Bronzo V., Castiglioni B. \& Boettcher P.J. 2006. Relationships between somatic cell count and intramammary infection in buffaloes. J. Dairy Sci. 89:998-1003.

Pardo R.B. 2007. Conteúdo celular do leite bubalino proveniente de quartos mamários sadios e portadores de mastite. Tese de doutorado, Faculdade de Ciências Agrárias e Veterinária, Universidade Estadual Paulista, Jaboticabal, SP. 80p.

Petrova N. \& Tzankova M. 1999. SCC of milk from three breeds of buffaloes in Shoumen region. Bulgarian J. Agric. Sci. 5:895-900.

Piccinini R., Miarelli M., Ferri B., Tripaldi C., Belotti M., Daprà V., Orlandini S. \& Zecconi A. 2006. Relationship between cellular and whey components in buffalo milk. J. Dairy Res. 73:129-133.

Quinn P.J., Carter M.E., Markey B.K. \& Carter G.R. 1994. Mastitis, p.327-344. In: Quinn P.J., Carter M.E., Markey B.K. \& Carter G.R. (Eds), Clinical Veterinary Microbiology. Wolfe Publishing, London.

Schalm O.W. \& Noorlander D.D. 1957. Experiments and observations leading to development of the California Mastitis Test. J. Am. Vet. Med. Assoc. 130:199-204.

Siegel S. \& Castellan Jr N.J. 2006. Estatística Não-paramétrica para as Ciências do Comportamento. $2^{a}$ ed. Artmed, Porto Alegre. 448p.

Silva N., Junqueira V.C.A. \& Silveira N.F.A. 1997. Manual de métodos de análise microbiológica de alimentos. Varela, São Paulo. 295p.

Silva I.D. \& Silva K.F.S.T. 1994. Total and differential cell counts in buffalo (Bubalus bubalis) milk. Buffalo J. 10:133-137.

Singh M. \& Ludri R.S. 2001. Somatic cell counts in Murrah buffaloes (Bubalus bubalis) during different stages of lactation, parity, and season. Asian-Australasian J. Anim. Sci. 14:189-192.

Singh A., Saini A.L. \& Randhawa S.S. 2002. Variation in somatic cell count in relation to udder health and milk quality in cross bred cows and buffaloes. J. Livestock Poult. Prod. 18:52-62.

Singh R.S., Bansal B.K., Randhawa S.S. \& Mavi P.S. 2004. Effect of lactation therapy on quarter infection and milk composition $\mathrm{n}$ specific mastitis of buffaloes. Indian J. Vet. Med. 24:16-18.

Tripaldi C., Terramoccia S., Bartocci S., Angelucci M. \& Danese V. 2003. The effects of the somatic cell count on yield, composition and coagulating properties of Mediterranean buffalo milk. Asian-Australasian J. Anim. Sci. 16:738-742.

Tuteja F.C., Kapur M.P., Sharma A. \& Manuja B. 2001. Mastitis pathogens from apparently healthy buffaloes and their relationship to somatic cell count of milk. Indian J. Comp. Microbiol. Immun. Infect. Dis. 22:162-163.

Vianni M.C.E., Nader Filho A., Rosseti D.J.G., Longhi J.L. \& Sicher M. 1990. Eficiência do Califórnia Mastitis Test (CMT) na estimativa do número de células somáticas do leite bubalino. Ciência Vet. 4:3-4.

Vivek S., Anshu S., Ravinder S. \& Ashok K. 2002. Comparison of various indirect tests for the detection of subclinical mastitis. Buffalo J. 18:267-271.

Zafalon L.F., Amaral L.A., Nader Filho A., Oliveira J.V., Resende F.D. \& Oliveira J.A. 1999. Influência de bactérias do gênero Corynebacterium e estafilococos coagulase positivos e negativos sobre a contagem de células somáticas e a produção láctea de quartos mamários com mastite clínica. Napgama 6:4-6.

Zar J.H. 1999. Biostatistical Analysis. $4^{\text {th }}$ ed. Prentice Hall, Upper Saddle River. 663p. 